ఠ

\title{
Evolutionary and neuropsychological perspectives on addictive behaviors and addictive substances: relevance to the "food addiction" construct
}

This article was published in the following Dove Press journal:

Substance Abuse and Rehabilitation

12 December 2014

Number of times this article has been viewed

\section{Caroline Davis}

School of Kinesiology and Health Science, York University, Toronto, ON, Canada
Correspondence: Caroline Davis School of Kinesiology and Health Science, 343 Bethune College, York University, 4700 Keele Street, Toronto, ON M3J IP3, Canada

Tel +I 4167362100 Ext 77327

Email cdavis@yorku.ca

\begin{abstract}
It has been argued that food cannot be "addictive", unlike conventional drugs of abuse, because it is an essential part of life. In this paper, evidence is reviewed, largely from an evolutionary psychobiological perspective, that plant-based psychoactive drugs (such as those derived from the opium poppy and the coca leaf) and gambling-related behaviors were once adaptive for human health and survival in a similar manner as energybased foods were for nourishment. "Evolutionary mismatch" viewpoints contend that certain behaviors were enhanced during the hunter-gatherer lifestyle - from which our genetic endowment had its origins - because they bestowed both survival and reproductive advantages to the species. However, in the context of advanced technology and other rapid environmental changes, these same behaviors have tended to become maladaptive and greatly overexpressed. Similar to the manufactured purification of psychotropic plant-based substances, the reward impact of processed and hyperpalatable foods, with their high levels of sugar, fat, and salt, is much increased from foods produced in nature. It is concluded therefore that what was once beneficial and necessary for our survival has been altered and ultraprocessed into edible products that may be disadvantageous and potentially addictive.
\end{abstract}

Keywords: food addiction, evolution, drugs, gambling

\section{Introduction}

Evolutionary psychobiology is a scientific perspective that involves the analyses of inherent neurobiological mechanisms that mediate the behavior of an organism; in other words, the "hows and whys" of adaptive behavioral responses to environmental pressures. Darwinian medicine is an extension of this endeavor, and entails the quest for evolutionary explanations for disease risk. ${ }^{1} \mathrm{~A}$ basic tenet of evolutionary science is that over time, human awareness and motivation has been shaped by natural selection, which produced biobehavioral characteristics that bestow a survival or fitness advantage to the species. ${ }^{2}$ In the broadest sense, "fitness" refers to an organism's ability to survive and successfully reproduce in its current environment, the consequence of which is that the organism contributes its genes to the next generation. ${ }^{3}$ Accordingly, humans are born with "innate cognitive blueprints" that are essential for their ability to prosper and produce progeny. ${ }^{2}$ Importantly, we also have an evolved capacity to experience considerable pleasure and happiness from these key adaptive pursuits, like eating and drinking, as well as mating and rearing children. 


\section{'Food Addiction'}

The notion that some individuals can become "addicted" to food has been widely accepted among the general population for decades, as shown, for example, by the founding in 1960 of Overeaters Anonymous, a program based on the 12-step approach first used to treat alcoholism. Despite increasingly persuasive clinical and scientific support in recent years for the view that some cases of overeating have striking behavioral and neurobiological similarities to substance(and nonsubstance)-abuse disorders (eg, compulsive intake in the face of adverse consequences, strong cravings, and withdrawal symptoms in the abstinent state) ${ }^{4-7}$ the foodaddiction construct has nevertheless also had its detractors. In their evaluation of the evidence, however, some critics have wrongly conflated obesity and binge eating with the notion of food addiction, a stance that has only served to muddle the debate. ${ }^{8}$ Others have, more plausibly, questioned the veracity of the concept, because "food", unlike "drugs", is necessary for human survival. Therefore, they argue, one cannot develop strategies to avoid it altogether, as a drug addict could toward cocaine or heroin or nicotine. ${ }^{9}$

In the recently published Diagnostic and Statistical Manual of Mental Disorders (DSM)-5, ${ }^{10}$ the existence of behavioral addictions was recognized, for the first time, in its chapter on substance-related and addictive disorders, although gambling disorder is currently the only condition listed in that category. Interestingly, prior to the DSM-5 and since 1980, pathological gambling was classified as an impulse-control disorder, distinct from substance-abuse and -dependence disorders. While other excessive behaviors related to sex, exercise, eating, and shopping had been considered for inclusion in the behavioral addiction category of the DSM-5, none was thought to have sufficient (researchbased) validation as a mental health problem at the time of publication. ${ }^{11}$

Gambling has always been the least contentious (nonsubstance) addictive behavior among members of the scientific community, as reflected, for example, in the history of the DSM. By contrast, eating and sex have been viewed more antagonistically as potentially addictive behaviors. ${ }^{12}$ This bias seems to mirror the popular belief that eating and sex are intrinsic to our well-being, while drug-taking and gambling are hedonistic, immoral, and supremely unnecessary activities. It may also be that the nonspecific and abstruse nature of the food-addiction label is a major impediment to its acceptance as a valid clinical entity. Indeed, we have argued elsewhere that this putative syndrome is unsuitably named - perhaps even an oxymoron - because the word "food" is mostly associated with positive attributes and connotes the quintessential element of human existence. "Addiction", on the other hand, implies pathology and even antisocial behavior. ${ }^{13}$ It may be much more appropriate to use terms like "hyperpalatable processed-food addiction" or "sweet, fatty, and salty food addiction", because the kinds of food that are perpetually craved and eaten to excess, and that comprise the vast majority of binge episodes, are not grown or raised in nature. Instead, they are exceedingly dense in calories from added fat, sugar, and salt, and are perceived by most as irresistibly appetizing. ${ }^{14}$ Others have also been critical of the food-addiction terminology and proposed the terms "eating addiction" or "addictive eating disorder" to highlight the behavioral disturbances associated with this compulsive overeating syndrome. ${ }^{15}$

Several comprehensive review papers have documented the experimental, preclinical, and clinical evidence that certain foods can mimic the behavioral and neurophysiological effects of addictive drugs, and importantly that the data for these findings come entirely from studies of highly palatable fare, and show more pronounced effects following periods of deprivation. ${ }^{4,16-18}$ Like all creatures, we have a strongly innate drive to acquire enough food to survive and to sustain ourselves during lean times; consequently, we have an evolved proneness to eat beyond caloric need and in the absence of physiologically driven hunger. There is little dispute, therefore, that the many highly processed foods can overwhelm brain-reward circuitry in a way that natural foods cannot, because of their sheer density of preferred nutrients. ${ }^{19}$ In other words, in the manufacture of these ultraprocessed foods, the potency of the ingredients that make them so appealing to our palate (ie, sugar, fat, and salt) has been increased multifold. In this regard, they display a strong likeness to highly purified drugs of abuse and contemporary forms of gambling, which also activate brain-reward pathways beyond their evolved "safety zone".

Less often considered in discussions of food addiction and debates about its conceptual legitimacy is that psychoactive plant substances and gambling-related activities were once comparable to natural rewards like food, because they also conferred a survival and/or reproductive (fitness) advantage. Hagen et al recently posed an important question when they queried the basis on which neuroscientists tend to classify drug reward as "abnormal" and food reward as "normal" when both activate the same mesocorticolimbic dopamine system, both produce strong approach and consumptive behaviors, both enhance well-being, and both foster the conditioning of cues that predict their availability. ${ }^{20}$ Moreover, these authors dispute the premise that so-called natural 
rewards like food and sex "activate" brain-reward circuitry, while addictive drugs "hijack" these same pathways. Just like many highly processed foods, what has made addictive drugs profoundly capable of altering neurobiological functioning - thereby shifting motivation and behavior toward compulsion and pathology - is their manufactured potency and easy availability.

In the following sections of this paper - and largely from an evolutionary viewpoint - evidence is reviewed that plant-based drugs and gambling-related behaviors were once adaptive for human survival in a similar way as nature's energy-based foods were for nourishment. Offering this perspective is intended to challenge the notion that "food" cannot be addictive in the same way as gambling, inhaling cocaine, or drinking alcohol, because unlike these activities, we cannot live without eating. The crux of the issue is that one is able to have a sufficient diet, with appropriate amounts of energy, vitamins, and minerals from required macro- and micronutrients, without consuming ultraprocessed foods, in the same way as one can live in modern societies without smoking nicotine or inhaling cocaine.

\section{An evolutionary interpretation of gambling behavior}

Taking chances and wagering on probabilistically uncertain outcomes are the core components of gambling, a form of risky behavior that is undertaken, in a myriad of different ways, to win resources, and that has pervaded all cultures as far back as prerecorded history. ${ }^{21,22}$ We have learned that such activities tend to be favored more by those with a venturesome predisposition, a proneness to precarious decision making, and a high capacity for reward. ${ }^{23-25}$ Collectively, these are stable individual-difference traits, with a clear biological basis in the general population. Undoubtedly, the historic persistence of gambling-related characteristics strongly bespeaks their evolutionary significance in the behavioral repertoire of most animals, including Homo sapiens.

In nonhuman studies, the unpredictability of a valuable stimulus seems to be more attractive than the delivery of a relatively certain reward. Pigeons, for example, will reliably select the option with a suboptimal probability of reinforcement $(20 \%)$ over another that provides a better $(50 \%)$ reinforcement, findings that are consistent with other Pavlovian experiments showing that a seldom-occurring conditioned stimulus (CS) results in more rapid learning than when the CS occurs more frequently. ${ }^{26}$ Interestingly, it was also found that pigeons reared in a socially enriched environment were less likely to prefer unpredictability than those animals reared in isolation. ${ }^{27}$ These findings mesh with human-research evidence that pathological gambling is more likely to develop in people who experience stressful situations and/or a lack of stimulation in their everyday lives. ${ }^{28}$ Such findings have been explained by the fact that poor environments typically resemble unpredictable environments, which are difficult to comprehend cognitively. Therefore, and according to the compensatory hypothesis, reward seeking is the best behavioral strategy in an unpredictable environment. ${ }^{28}$

It has also been shown that dopamine activation and release in reward pathways is sustained during the interval between the CS and delivery of the reward - a time when there is maximal uncertainty about its arrival - while the dopamine-activation level is similar to baseline when the reward is actually delivered. These findings suggest that dopamine release is an important learning/teaching signal, and therefore has a multiple and essential role in the acquisition of survival behaviors. ${ }^{29}$ In essence, dopamine is, as well as other things, a signal of "surprise", because its release is triggered by unexpected rewards to a greater degree than when the reward is perfectly predictable. Thereby, its action assists the organism in learning the value of a particular stimulus, and what actions will enhance the likelihood of acquiring future rewards in a particular circumstance. ${ }^{30}$ If reward unpredictability was not a highly motivating event, important survival behaviors would be extinguished because of the high failure rate experienced by animals in acquiring the necessities of life. ${ }^{28}$ Typically, these behaviors are not extinguished by failures and losses, but instead the lack of success tends to arouse and enhance an animal's interest in relevant reward-seeking activities. Such motivational processes are therefore an evolutionary strategy "that consists of compensating the difficulty to predict significant objects and events in a given context" ${ }^{28}$

The ability to survive in an uncertain world requires an innate facility for achieving a successful balance between the exploitation of known resources (ie, predictable options) and the exploration of one's surroundings (ie, riskier choices), in order to learn about the potential for more valuable options elsewhere. ${ }^{31}$ It is the exploration strategy that underlies behavioral choices in human gambling activities. Not only are these strategies strongly predisposed in human phylogeny, but there are pronounced individual differences in preference for exploration versus exploitation approaches. Take, for example, the evidence of more variation in reproductive fitness in males than in females - that is, compared to females whose reproductive success is relatively homogeneous, many males fail 
to reproduce at all, while some reproduce at relatively high rates. $^{21}$ These sex differences have been used to explain in part why males are inherently more prone to taking chances, while females tend to be more risk-averse. ${ }^{32}$

Current gambling addictions, which are increasingly prevalent in modern society, can be explained in a manner similar to the relatively recent emergence of excessive and compulsive overeating, and according to "evolutionary mismatch" viewpoints. The basic tenets of this theory are that certain behaviors were enhanced during human evolution - and the hunter-gatherer lifestyle from which our genetic endowment had its origins - because they conferred both survival and reproductive advantages to the species. However, in the context of an environment rapidly changed, these same behaviors have become maladaptive and overexpressed. ${ }^{33}$ Due to a broad range of technological advances in agriculture and industry, environmental changes in the past century or so have occurred much more rapidly than was observed in prehistoric times.

As noted earlier, the allure of chance is at the heart of gambling, and can be a highly rewarding stimulus. Especially when reinforcement is given randomly and intermittently, interest in the stimulus is aroused and sustained. ${ }^{34}$ Current arenas for gambling, such as Las Vegas-style casinos, Internet sites, and the increasing number of weekly cash lotteries, have been designed to create intense visual and auditory stimuli, which are quickly conditioned to signal gains and rewards to the participants. ${ }^{34}$ In other words, due to their increased salience and potency, hyperrewarding stimuli can transform evolved stratagems for survival into compulsions that compromise health and well-being.

\section{Plant substances as medicinal "food": a coevolutionary viewpoint}

Many botanical materials produce a range of chemicals, including alkaloids, which have been used historically to promote health in a variety of ways. ${ }^{35}$ It is well-established that humans have frequently and deliberately ingested plant substances for medicinal purposes. ${ }^{36}$ In this regard, Hagen et al have argued compellingly that the human brain evolved to control and regulate intake of a broad range of psychoactive plant toxins in order to promote reproductive fitness and to minimize fitness costs. ${ }^{20}$ For instance, our genetic ancestors regularly and knowingly consumed small amounts of potentially lethal substances, which had no macronutrient content, despite signals of toxicity like their bitter taste or nauseating effects. ${ }^{20}$ Indeed, under certain conditions, other mammals are also known to consume certain plants with low nutritional value, but which contain highly bioactive compounds.
An important evolutionary question is why animals, including humans, learned to ignore signs of plant toxicity like bitter taste and aversive side effects in order to consume potentially lethal substances that essentially have no energy content. ${ }^{20}$ A core premise of evolutionary theory is that a trait cannot evolve unless it contributes to overall reproductive success. Therefore, there must have been an advantageous trade-off for the risk associated with the ingestion of potentially toxic substances. As with modern therapeutic drugs, when certain plant substances are ingested in small amounts and below their toxic threshold, they can be helpful in maintaining health or aiding in disease recovery. ${ }^{37}$ For instance, certain plants evolved the ability to synthesize alkaloid compounds, such as caffeine and nicotine, which on the one hand served as neurotoxins to deter their consumption by herbivores, but on the other hand also provided benefits to those who did ingest them (as discussed in sections to follow).$^{38}$ Collectively, such behaviors suggest a type of natural self-medication. ${ }^{37}$ They also infer an "instrumentalization" role for certain substances that historically served various adaptive functions for reproduction and survival. ${ }^{39}$ It can be argued therefore that we evolved a genetically determined predisposition for drug use. It has been the purification of psychotropic plant ingredients, however, and their ready availability in many societies globally, that have led to an increased propensity for problem drug use. The risk for dependence and abuse is consequently an environmentally induced fallout of our once-adaptive preferences for these natural substances.

\section{Ethanol and ripened fruit}

The human preference for sweet taste is an innate characteristic that has evolved to activate pleasure-generating brain mechanisms that are phylogenetically very well preserved. ${ }^{40}$ Prehistorically, sugars provided various evolutionary advantages. For instance, they have been shown to have natural analgesic properties in infants and children, they signal the likely absence of toxicity in the food source, and they provide a prompt source of energy to the organism, since the mammalian brain uses only glucose as a source of energy. ${ }^{41,42}$ It is believed that in turn fruits evolved a richness of sugar to promote their consumption by herbivores as a way of dispersing seeds. ${ }^{43}$

Ethanol is a naturally occurring substance that is produced in ripe and overripe fruits where the sugar and starch components of the plant undergo yeast fermentation. Therefore, our preference for selectively consuming ripe over unripe fruits demonstrates another evolutionary adaptation, because the 
alcohol plumes radiating from ripe fruit help in the localization of this food source. ${ }^{44}$ There are also antibacterial properties associated with eating fermenting fruits. ${ }^{45}$ Furthermore, consumption of small traces of ethanol acts as an appetite stimulant: another beneficial adaptation given the valuable nutritional resources found in ripe fruit. In addition, it can facilitate social behavior, which is conducive to reproduction and safety. Even small amounts of alcohol have the ability to reduce social inhibition, anxiety, and discomfort, and to increase communication and intimacy. ${ }^{39}$

The presence of ethanol in ripe fruit suggests that chronic albeit low-level exposure to this substance must have occurred in all frugivore species, which in turn would have favored the evolution of physiological advantages of alcohol ingestion while minimizing related costs. ${ }^{46}$ It has been suggested therefore that modern humans have almost certainly evolved a preference for alcohol because our historical ancestors derived from frugivorous primates who had a sensory bias associating fruit-derived alcohol with nutritional reward. ${ }^{46}$

The availability of alcohol at concentrations higher than those achieved by yeast fermentation alone has occurred only relatively recently in human history as a result of distillation and purification processes. ${ }^{44}$ These changes in potency have clearly increased the population odds of alcohol misuse and dependence. Other factors have also contributed importantly to the increased prevalence of hazardous drinking and alcoholism. For instance, the powerful alcohol industry has played a key role in promoting alcohol use through its lobby against tax increases, against restrictions on availability, and against advertising regulations. ${ }^{47}$ On the other hand - and in order to try and enhance its status as a good corporate citizen - the alcohol industry has also provided support for educational interventions, despite compelling evidence that educational approaches are largely ineffective in changing drinking behaviors. ${ }^{48}$ In many countries, the public sale of alcohol is not restricted to just bars and restaurants, but occurs at a host of community venues like sporting arenas, fairgrounds, and centers for the performing arts. Such liberal access to alcohol at relatively low cost with full legal sanction makes this drug more available than all illicit substances and other legal drugs like nicotine.

\section{Nicotine}

In the coevolution between flora and fauna, some plants developed the capacity to synthesize neurotoxic alkaloids like nicotine in order to deter their own consumption by humans and other animals. ${ }^{38}$ In a relationship that was essentially antagonistic, but also mutually beneficial, herbivores in turn regularly used such plant toxins to improve their health and well-being: a process that has been variously called "selfmedication" or "pharmacophagy". ${ }^{36}$ Contrary to public opinion, however, nicotine consumption is not a modern invention, but was widely used by hunter-gathers in the Americas for millennia. ${ }^{49}$

Alkaloids like nicotine not only tend to improve performance and concentration and enhance $\operatorname{mood}^{50}$ but are also known to have effective antiparasitic properties, ${ }^{51}$ and were ingested by our herbivore ancestors as a defense against their own helminth infections. ${ }^{52}$ Helminthiasis is the infestation of intestinal parasitic worms (eg, roundworms or hookworms) whose eggs are secreted via human feces and in turn contaminate the soil in areas with poor sanitation. This condition was historically, and continues to be, a pressing global health problem, because it compromises nutritional status and can also impair cognitive processes. ${ }^{53}$ Indeed, it has been proposed that the human propensity to consume neurotoxic plant substances may have evolved in large part as a type of chemoprophylaxis and/or as a form of chemotherapy to combat dangerous parasite infections. ${ }^{36}$

In a recent and innovative study designed to test the self-medication hypothesis regarding the recreational use of tobacco, the Aka - a group of Central African foragers who regularly smoke tobacco and who also have very high rates of helminth infections - were studied longitudinally. ${ }^{36}$ Importantly for the purposes of this study, the Aka are not aware of the medicinal benefits associated with nicotine use. Findings indicated that higher nicotine exposure was associated with a significantly lower "worm burden" among the adults tested. Moreover, in a subset of the sample who were treated with an effective commercial antiparasitic drug (albendazole), those with higher cotinine (a metabolite of nicotine and biomarker for exposure to nicotine) concentrations in the blood in the first year after treatment had lower reinfection rates in the second year. Together, these results provide support for the chemoprophylaxis hypothesis of nicotine use.

Nicotine is a notable example of a plant-based substance whose use was not problematic and did not lead to tobacco addiction until dramatic production and processing changes took place during the middle of the nineteenth century, events that increased the potency of tobacco and led to the greatly increased manufacturing capacity of cigarettes. In an interesting treatise on the history of tobacco, Slade describes the industrial innovations that caused the "greatest epidemic of the twentieth century". ${ }^{54}$ For instance, the development of flue-curing at very high temperatures reduced the nitrogenous 
material and increased the sugar content in the tobacco leaf, thereby making its smoke easier to inhale. Early mechanized cigarette rollers were still labor-intensive until the invention in 1884 of a machine that increased production from approximately 3,000 cigarettes a day to 120,000 , causing availability to increase and prices to fall. And finally, the perfection of the friction match ensured that smoking could take place virtually anywhere.

\section{Other plant alkaloids}

The opium poppy (Papaver somniferum) is an ancient but still heavily used medicinal plant, which has been cultivated in eastern Mediterranean countries like Turkey since prehistoric times, and was profoundly important in the culture and diets of people in these regions for its important role in counteracting the deleterious effects of pain. ${ }^{55}$ Archaeological findings have also revealed the widespread use of opium for cult rituals and for its healing and soporific properties. ${ }^{56}$ Opium is the dried "milk" of the poppy capsule, which comprises approximately $12 \%$ morphine with lesser amounts of codeine, and is the sole source of these key pharmaceuticals. ${ }^{57}$ In other words, the opium poppy is the only commercial source of morphine and codeine, because this type of alkaloid precludes chemical synthesis as a marketable and affordable option. ${ }^{58}$ Historically, benzylisoquinoline alkaloids like morphine and codeine from the opium poppy were typically obtained by manual extraction, but harvests were generally small because these compounds accumulate in relatively low levels in plant cells. ${ }^{35}$ Therefore, our genetic ancestors would only have received trace levels of these chemicals.

Opium and other poppy-derived opiates, such as heroin, have now become major drugs of abuse, with a global production of illicit manufacture. Through purification processes using chemical extraction, morphine was first produced in the early nineteenth century by Friedrich Sertürner, and is believed to be the first isolation of a plant alkaloid in history. ${ }^{59}$ Since then, advanced technology has produced greater supplies and more purified end products, while metabolic engineering and selective breeding have been used to increase the content of alkaloid levels like morphine in the latex of the plant. Morphine is now easily turned into heroin by chemical production, a process that effectively increases its potency to twice that of morphine. The opium poppy is indeed a poignant example of a plant-based compound that through human ingenuity has provided both great positive and great negative value to humankind. ${ }^{58}$

Cocaine is another psychotropic plant substance, which derives from the Erythroxylum coca leaf and has been consumed in many regions of South and Central America since prehistory. It has been noted that for millennia, people have sought out as food plant species that contained disproportionate amounts of secondary chemicals that provided benefits beyond being a source of calories and macro/micronutrients. The ancient practice of chewing the coca leaf exploited the cocaine content in this plant for use as a local anesthetic, and to combat the deleterious consequences of high altitude. ${ }^{60}$ The behavioral effects of this medicinal alkaloid also importantly include increases in stamina and attentional focus and the suppression of appetite, outcomes that were clearly adaptive during periods of hunting and foraging, in times of food scarcity, and during long migrations to suppress fatigue and cravings when food was scarce. ${ }^{45}$ In addition, plants like the coca leaf provided neurotransmitter precursors like tryptophan and tyrosine when high-quality food (eg, meat) was not available. ${ }^{61}$ Moreover, the coca leaf also functioned as food, in that it is rich in many essential minerals (eg, calcium and iron) and vitamins (eg, A, B ${ }_{2}$, and E). ${ }^{61}$ Once again, through the ingenuity of mankind, this psychotropic substance has been condensed and significantly purified into powder and crystals that are magnitudes stronger and more potent than the substance used beneficially - albeit in trace amounts - by our ancestral forbears.

In conclusion, it should also be noted that historically both cocaine and opium were generally only problematic to localized immigrant groups until each of these products was processed and transformed into more transportable, longerlasting, and more potent products. In other words, it was essentially the development of highly processed drugs that led to the addiction problem as we think of it today.

\section{Processed foods as modern "drugs"}

The popular press, as well as the scientific and medical community, has often vilified processed foods for their role in providing a poor-quality diet and for their contribution to rapidly increasing health problems like diabetes and cardiovascular disease. In discussing these issues, however, it is important to be specific about the impugned "culprit" and the criticisms levied at it. Simply stated, food processing refers to the mechanical or chemical alteration of a particular food from the state in which it was grown or raised, by means of some preserving technique to avoid spoilage. It is also an ageold technology that has existed since prehistoric times, and whose original purpose was to enable access to energy stores during times of scarcity. ${ }^{62}$ As such, it has helped to ensure that sufficient food is available to feed global communities. In other ways, food processing has also contributed to the 
health of global populations. For example, if not for the fortification and enrichment of such foods as bread and milk, large proportions of the population would have deficiencies of vitamins like A, C, D, and E, and minerals like iron, calcium, magnesium, and folate. ${ }^{62}$ It is clear, therefore, that it is the kind of alterations made to the food that determine their merits and demerits.

Until relatively recently, most preserving and processing of food took place in the home. However, with the advent of large-scale industrial food processing and the capitalist enterprise, technologies changed dramatically to accommodate the quest for commercial success and to gain the "competitive edge". Enhancing the palatability of foods is at the heart of food marketers' strategies to increase revenue at the retail level. Consumption of sugar, for example, has tripled worldwide in the last half century, largely because it has been added to nearly all processed foods. ${ }^{63}$ Over the past 3 to 4 decades, the proportion of household consumption of ultraprocessed foods - those products that are ready to eat or ready to heat - has steadily replaced unprocessed/minimally processed foods. ${ }^{64}$ The former are typically characterized by greater energy density, and contain significantly more added sugar, saturated fat, and sodium than the latter. Carbonated soft drinks and commercial baked goods appear to be the most significant vectors for sugar and salt, while added oils contribute to the high fat content in much of the ultraprocessed and highly palatable foods we consume today. ${ }^{65}$ Of all these added ingredients, many believe that sugar - ie, any sweetener containing fructose that is supplemented via food processing - is the primary component contributing to the addictive potential of some foods. For instance, in an examination of the components of a typical "fast food" meal, it was concluded that while added fat and salt tend to increase the salience of the food, it is the sugar and caffeine that foster its compulsive intake. ${ }^{66}$

The most problematic sugar seems to be fructose, which has increased globally, at least threefold in the last century. ${ }^{67}$ Evidence suggests that dietary fructose is not required for any human biochemical reaction; moreover, in the quantities we consume it, there are various negative effects on human metabolism, such as an undermining of normal satiety signals. ${ }^{68}$ There are also compelling arguments that fructose is simply "alcohol without the buzz", because the latter is produced by the fermentation of fructose. ${ }^{68}$ In fact, the similarities between sugar and alcohol are particularly strong, because both have a strong potential for abuse. Interestingly, although comparative data are very limited, population prevalence rates of "food addiction" (as diagnosed by the frequently used Yale Food Addiction Scale) ${ }^{69}$ and alcoholism appear to be approximately the same: between 5\% and $10 \%$ of the population. ${ }^{70,71}$ It has also been found that a hedonic responsiveness to sweet taste is positively correlated with a propensity to drink alcohol excessively and with the genetic risk for alcoholism. ${ }^{72}$

Although ultraprocessed foods do not produce the inebriation caused by alcohol or the euphoria some experience from stimulant drugs like cocaine, they nevertheless have pronounced parallels with conventional addictive drugs. For instance, both have the capacity for triggering cravings, and are associated with compulsive consumption and the inability to cut down, even when the consequences are knowingly dire. ${ }^{73}$ Similarly to the downwardly spiraling process of drug addiction, excessive stimulation of the brain's common reward pathway - a core mechanism of human survival - by foods made highly palatable by the addition of sugar, fat, and salt contributes to increasingly compulsive consumption. In turn, the effects of tolerance and reduced inhibitory control may prompt even more frequent and more prodigious intake, contributing to an interdependent series of behaviors that tend to become more severe over time.

\section{Conclusion}

In summary, there is good evidence that humans have shared a 200 million-year coevolutionary relationship with psychotropic plant chemicals, ${ }^{61}$ and that most popular addictive drugs are derived from plant neurotoxins or their close chemical analogs. ${ }^{20}$ As reviewed in this paper, there is considerable historical evidence of the deliberate use by humans of plant materials for medicinal/self-medication purposes. In our ancestral environment, "drugs" were simply plants and therefore were consumed alongside other more energy-rich foods. ${ }^{61}$ Unlike current times, the biologically active compounds found in plants would have been scarce in hunter-gatherer environments. Through cultivation, purification, and chemical modification, however, these same substances have increased in concentration, and are now plentiful and highly potent. ${ }^{45}$ In addition, there are many "novel psychoactive compounds" that are manufactured as substitutes for plant-based compounds like cocaine, ${ }^{74}$ or as synthetic alternatives, such as the dozens and dozens of manmade cannabinoids. ${ }^{75}$ Consequently, pharmacophagic qualities that would once have conferred a survival advantage in our "environment of evolutionary adaptation" appear to diminish reproductive fitness in our current surroundings through excessive and sometimes compulsive use. ${ }^{45}$ In other words, even if substance-seeking from medicinal plants was a 
process of adaptive self-medication for our hominid ancestors, it is not necessarily so in our contemporary environment for the reasons stated earlier. ${ }^{61}$

Over time, and via cultivation, manufacturing, and advanced technology, certain processed foods have also acquired the strength to sabotage healthy brain function and override well-regulated and adaptive behaviors. In other words, they can overpower normal brain mechanisms and divert them from guiding human behaviors in advantageous directions. ${ }^{76}$ What has happened to the foods that comprise much of our current diet is directly parallel to the transformation of other once-adaptive substances and behaviors to forms that are highly addictive and potentially dangerous. In a similar feat of insidious contrivance, the reward impact of food has been magnified multifold by the addition of sugars, fats, and salt, as well as other taste enhancers like monosodium glutamate.

Therefore - and in the context of the rise in global rates of obesity, for instance - genetically-based predispositions that were once beneficial have become disadvantageous in environments that provide ad libitum and superfluous access to nutritional substances. As Lustig et al stated poignantly about sugar, "... nature made [it] hard to get; man made it easy":63 so can the same be said of all potentially addictive substances derived from plant materials.

\section{Acknowledgments}

The author wishes to thank very much the two anonymous reviewers who reviewed and offered exceedingly insightful suggestions on an earlier draft of this paper. I am indebted to them for their very helpful comments.

\section{Disclosure}

The author reports no conflicts of interest in this work.

\section{References}

1. Hill Em, Newlin DB. Evolutionary approaches to addiction: introduction. Addiction. 2002;97:375-379.

2. Saad G. Evolutionary consumption. J Consum Psychol. 2013;23: 351-371.

3. Orr AH. Fitness and its role in evolutionary genetics. Nat Rev Genet. 2009;10:531-539.

4. Davis, C. From passive overeating to "food addiction": a spectrum of compulsion and severity. ISRN Obesity. 2013;2013:435027.

5. Heymsfield SB, Avena NM, Baier L, et al. Hyperphasia: current concepts and future directions. Proceedings of the 2nd International Conference on Hyperphasia. Obesity (Silver Spring). 2014;22 Suppl 1:S1-S17.

6. Pai N, Vella SL, Richardson K. Is food addiction a valid phenomenon through the lens of the DSM-5? Aus N ZJ Psychiatry. 2014;48: 216-218.

7. Salamone JD, Correa M. Dopamine and food addiction: lexicon badly needed. Biol Psychiatry. 2013;73:E15-E24.

8. Ziauddeen H, Fletcher PC. Is food addiction a valid and useful concept? Obes Rev. 2013;14:19-28.

9. Krashes MJ, Kravitz AV. Optogenetic and chemogenetic insights into the food addiction hypothesis. Front Behav Neurosci. 2014;8:57.
10. American Psychiatric Association. Diagnostic and Statistical Manual of Mental Disorders. 5th ed. Washington: American Psychiatric Association Press; 2013.

11. Potenza MN. Non-substance addictive behaviors in the context of DSM-5. Addict Behav. 2014;39:1-2.

12. Zhang Y, Tian J, von Deneen KM, Liu YJ, Gold MS. Process addictions in 2012: food, internet and gambling. Neuropsychiatry. 2012;2:155-161.

13. Davis C, Levitan RD, Kaplan AS, Kennedy JL, Carter JC. Food cravings, appetite, and snack-food consumption in response to a psychomotor stimulant drug: the moderating effect of "food addiction". Front Psychol. 2014;5:403.

14. Curtis C, Davis C. A qualitative study of binge eating disorder and obesity from an addiction perspective. Eat Disord. 2014;22:19-32.

15. Hebebrand J, Albayrak O, Adan R, et al. "Eating addiction", rather than "food addiction", better captures addictive-like eating behavior. Neurosci Biobehav Rev. 2014;47C:295-306.

16. Albayrak O, Wölfle SM, Hebebrand J. Does food addiction exist? A phenomenological discussion based on the psychiatric classification of substance-related disorders and addiction. Obes Facts. 2012;5:165-179.

17. Corwin RL, Avena NM, Boggiano MM. Feeding and reward: perspectives from three rat models of binge eating. Physiol Behav. 2011;104:87-97.

18. Davis C, Carter JC. If certain foods are addictive, how might this change the treatment of compulsive overeating and obesity? Curr Addict Rep. 2014;1:89-95.

19. Kenny PJ. The food addiction. Sci Am. 2013;309:44-49.

20. Hagen EH, Roulette CJ, Sullivan RJ. Explaining human recreational use of 'pesticides': the neurotoxin regulation model of substance use vs the hijack model and implications for age and sex differences in drug consumption. Front Psychiatry. 2013;4:142.

21. Gray PB. Evolutionary and cross-cultural perspectives on gambling. J Gambl Stud. 2004;20:347-371.

22. Schwartz DG. Roll the Bones: The History of Gambling. New York: Gotham; 2006.

23. Penolazzi B, Gremigni P, Russo PM. Impulsivity and reward sensitivity differentially influence affective and deliberative risky decision making. Pers Individ Dif. 2012;53:655-659.

24. Shenassa ED, Paradis AD, Dolan SL, Wilhelm CS, Buka SL. Childhood impulsive behavior and problem gambling by adulthood: a 30-year prospective community-based study. Addiction. 2012;107:160-168.

25. Bernow N, Yakushev I, Landvogt C, et al. Dopamine D2/D3 receptor availability and venturesomeness. Psychiatry Res. 2011;193:80-84.

26. Stagner JP, Zentall TR. Suboptimal choice behavior by pigeons. Psychon Bull Rev. 2010;17:412-416.

27. Pattison KF, Laude JR, Zentall TR. Environmental enrichment affects suboptimal, risky, gambling-like choice by pigeons. Anim Cogn. 2013;16: 429-434.

28. Anselme P. Dopamine, motivation, and the evolutionary significance of gambling-like behaviour. Behav Brain Res. 2013;256:1-4.

29. Fiorillo CD, Tobler PN, Schultz W. Discrete coding of reward probability and uncertainty by dopamine neurons. Science. 2003;299: 1898-1902.

30. Piglieri F, Addessi E, De Petrillo F, et al. Nonhuman gamblers: lessons from rodents, primates, and robots. Front Behav Neurosci. 2014;8:33.

31. Laureiro-Martínez D, Canessa N, Brusoni S, et al. Frontopolar cortex and decision-making efficiency: comparing brain activity of experts with different professional background during an exploration-exploitation task. Front Hum Neurosci. 2014;7:927.

32. Sapienza P, Zingales L, Maestripieri D. Gender differences in financial risk aversion and career choices are affected by testosterone. Proc Natl Acad Sci U S A. 2009;106:15268-15273.

33. Nesse RM, Williams GC. Why We Get Sick. New York: Random House; 1994.

34. Spinella M. Evolutionary mismatch, neural reward circuits, and pathological gambling. Int J Neurosci. 2003;113:503-512. 
35. Minami H. Fermentative production of plant benzylisoquinoline alkaloids in microbes. Biosci Biotechnol Biochem. 2013;77:1617-1622.

36. Roulette CJ, Mann H, Kemp BM, et al. Tobacco use vs helminths in Congo basin hunter-gatherers: self-medication in humans? Evol Hum Behav. 2014;35:397-407.

37. Masi S, Gustafsson E, Saint Jalme M, et al. Unusual feeding behavior in wild great apes, a window to understand origins of self-medication in humans: role of sociality and physiology on learning process. Physiol Behav. 2012;105:337-349.

38. Sullivan RJ, Hagen EH, Hammerstein P. Revealing the paradox of drug reward in human evolution. Proc Biol Sci. 2008;275:1231-1241.

39. Müller CP, Schumann G. Drugs as instruments: a new framework for nonaddictive psychoactive drug use. Behav Brain Sci. 2011;34:293-347.

40. Drewnowski A, Mennella JA, Johnson SL, Bellisle F. Sweetness and food preference. J Nutr. 2012;142:1142S-1148S.

41. Lieberman LS. Dietary, evolutionary, and modernizing influences on the prevalence of type 2 diabetes. Ann Rev Nutr. 2003;23:345-377.

42. Stevens B, Yamada J, Ohlsson A. Sucrose for analgesia in newborn infants undergoing painful procedures. Cochrane Database Syst Rev. 2004;1:CD001069.

43. Brüne M. Substance abuse and substance dependence. In: Brüne M. Textbook of Evolutionary Psychiatry: The Origins of Psychopathology. Oxford: Oxford University Press; 2008:169-183.

44. Dudley R. Fermenting fruit and the historical ecology of ethanol ingestion: is alcoholism in modern humans an evolutionary hangover? Addiction. 2002;97:381-388.

45. St John-Smith P, McQueen D, Edwards L, Schifano F. Classical and novel psychoactive substances: rethinking drug misuse from an evolutionary psychiatric perspective. Hum Psychopharmacol. 2013;28:394-401.

46. Dudley R. Ethanol, fruit ripening, and the historical origins of human alcoholism in primate frugivory. Integr Comp Biol. 2004;44: 315-323.

47. Bosque-Prous M, Espelt A, Guitart AM, Bartroli M, Villalbí JR, Brugal MT. Association between stricter alcohol advertising regulations and lower hazardous drinking across European countries. Addiction. 2014;109:1634-1643.

48. Casswell S. Vested interests in addiction research and policy. Why do we not see the corporate interests of the alcohol industry as clearly as we see those of the tobacco industry? Addiction. 2013;108: 680-685.

49. Winter JC, editor. Tobacco Use by Native North Americans: Sacred Smoke and Silent Killer. Norman (OK): University of Oklahoma Press; 2000.

50. Warburton DM. Aspects of nicotine utilization. Behav Brain Sci. 2011;34:326-327.

51. Suárez-Rodríguez M, López-Rull I, Garcia CM. Incorporation of cigarette butts into nests reduces ectoparasite load in urban birds: new ingredients for an old recipe? Biol Lett. 2013;9:20120931.

52. Roulette CJ, Hagen EH. Tobacco, cannabis, parasites, and life history strategies in hunter-gatherers from the Central African Republic. Am J Phys Anthropol. 2012;147:253-253.

53. Strunz EC, Addiss DG, Stocks ME, Ogden S, Utzinger J, Freeman MC. Water, sanitation, hygiene, and soil-transmitted helminth infection: a systematic review and meta-analysis. PLoS Med. 2014;3:e10011620.

54. Slade J. The tobacco epidemic: lessons from history. J Psychoactive Drugs. 1992;24:99-109.
55. Evered KT. Traditional ecologies of the opium poppy and oral history in rural Turkey. Geogr Rev. 2011;101:164-182.

56. Askitopoulos H, Ramoutsaki IA, Konsolaki E. Archaeological evidence of the use of opium in the Minoan world. Int Congr Ser. 2002;1242: 23-29.

57. Page JE. Silencing nature's narcotics: metabolic engineering of the opium poppy. Trends Biotechnol. 2005;23:331-333.

58. Beaudoin GA, Facchini PJ. Benzylisoquinoline alkaloid biosynthesis in opium poppy. Planta. 2014;240:19-32.

59. Hamilton GR, Baskett TF. In the arms of Morpheus: the development of morphine for postoperative pain relief. Can J Anesth. 2000;47: 367-374.

60. Rivera MA, Aufderheide AC, Cartmell LW, Torres CM, Langsjoen O. Antiquity of coca-leaf chewing in the South Central Andes: a 3,000 year archaeological record of coca-leaf chewing from Northern Chile. J Psychoactive Drugs. 2005;37:455-458.

61. Sullivan RJ, Hagen EH. Psychotropic substance-seeking: evolutionary pathology or adaptation? Addiction. 2002;97:389-400.

62. Weaver CM, Dwyer J, Fulgoni VL 3rd, et al. Processed foods: contributions to nutrition. Am J Clin Nutr. 2014;99:1525-1542.

63. Lustig RH, Schmidt LA, Brindis CD. Public health: the toxic truth about sugar. Nature. 2012;482:27-29.

64. Monteiro CA, Levy RB, Claro RM, de Castro IR, Cannon G. Increasing consumption of ultra-processed foods and likely impact on human health: evidence from Brazil. Public Health Nutr. 2011;14:5-13.

65. Baker P, Friel S. Processed foods and the nutrition transition: evidence from Asia. Obes Rev. 2014;15:564-577.

66. Garber AK, Lustig RH. Is fast food addictive? Curr Drug Abuse Rev. 2011;4:146-162.

67. Vos MB, Kimmon JE, Gillespie C, Welsh J, Blanck HM. Dietary fructose consumption among US children and adults: the Third National Health and Nutrition Examination Survey. Medscape J Med. 2008;10:160.

68. Lustig RH. Fructose: it's "alcohol without the buzz". Adv Nutr. 2013;4: 226-235.

69. Gearhardt AN, Corbin WR, Brownell KD. Preliminary validation of the Yale Food Addiction Scale. Appetite. 2009;52:430-436.

70. Grant BF, Dawson DA, Stinson FS, Chou SP, Dufour MC, Pickering RP. The 12-month prevalence and trends in the DSM-IV alcohol abuse and dependence: United States, 1991-1992 and 2001-2002. Drug Alcohol Depend. 2004;74:223-234.

71. Pedram P, Wadden D, Amini P, et al. Food addiction: its prevalence and significant association with obesity in the general population. PLoS One. 2013;8:e74832.

72. Kampov-Polevoy AB, Boland EG, Khalitov E, Crews FT. Sweet liking, novelty seeking, and gender predict alcoholic status. Alcohol Clin Exp Res. 2004;28:1291-1298.

73. Davis C, Carter JC. If certain foods are addictive, how might this change the treatment of compulsive overeating and obesity? Curr Addict Rep. 2014;1:89-95

74. Corrazza O, Demetrovics Z, van den Brink W, Schifano F. 'Legal highs' an inappropriate term for 'novel psychiatric drugs' in drug prevention and scientific debate. Int J Drug Policy. 2013;24:82-83.

75. Fattore L, Fratta W. Beyond THC: the new generation of cannabinoid designer drugs. Front Behav Neurosci. 2011;5:60.

76. Nesse RM, Berridge KC. Psychoactive drug use in evolutionary perspective. Science. 1997;278:63-66.

Substance Abuse and Rehabilitation

\section{Publish your work in this journal}

Substance Abuse and Rehabilitation is an international, peer-reviewed, open access journal publishing original research, case reports, editorials, reviews and commentaries on all areas of addiction and substance abuse and options for treatment and rehabilitation. The manuscript management system is completely online and includes a very quick and fair

peer-review system. Visit http://www.dovepress.com/testimonials.php to read real quotes from published authors. 